\title{
Characterization of O-polysaccharide specific monoclonal antibodies derived from mice infected with the rough Brucella melitensis strain B115
}

\author{
Axel Cloeckaert, ${ }^{1 *}$ Michel S. Zygmunt, ${ }^{2}$ Gerard Dubray ${ }^{2}$ and Joseph N. LimeT ${ }^{3}$ \\ ${ }^{1}$ Unit of Experimental Medicine, Catholic University of Louvain, 75 avenue Hippocrate, B-1200 Brussels, Belgium \\ ${ }^{2}$ Institut National de la Recherche Agronomique, Laboratoire de Pathologie Infectieuse et d'Immunologie, \\ 37380 Nouzilly, France \\ ${ }^{3}$ Facultés Universitaires Notre Dame de la Paix, 61 rue de Bruxelles, 5000 Namur, Belgium
}

(Received 2 November 1992; revised 1 March 1993; accepted 5 March 1993)

\begin{abstract}
Twenty-two monoclonal antibodies (mAbs) specific for smooth lipopolysaccharide (S-LPS) were generated by fusion of spleen cells from mice infected with the rough Brucella melitensis strain B115 with the NSO myeloma. According to reactivity in enzyme-linked immunosorbent assay (ELISA) with O-polysaccharide (O-PS) and absence of reactivity with rough lipopolysaccharide (R-LPS), it was postulated that these mAbs recognized epitopes present on the O-PS. Most of the mAbs reacted equally well in ELISA and immunoblotting with S-LPS types of Brucella $A$ and $M$ dominant strains and were designated as specific for common (C) epitopes. Three mAbs were highly specific for $M$ dominant S-LPS. All these mAbs, in contrast to a mAb specific for the A epitope, showed little or no cross-reactivity with Yersinia enterocolitica O:9 S-LPS. S-LPS of B. melitensis B115 was extracted and analysed by immunoblotting and ELISA with mAbs specific for $A, M$ and $C$ epitopes. Reactivity of the mAbs with this S-LPS was compared to reactivity with S-LPS of A and M dominant smooth Brucella strains. The results suggest that S-LPS of $B$. melitensis B115 bears mainly $C$ epitopes and a few $M$ epitopes. The very weak reactivity of this S-LPS with the $m A b$ specific for the $A$ epitope and the fact that the $m A$ bs specific for $C$ and $M$ epitopes showed little or no cross-reactivity with $Y$. enterocolitica O:9 S-LPS suggest that O-PS from this rough strain could be used to distinguish $Y$. enterocolitica $O: 9$ infection from Brucella infection. The potential value of the rough $B$. melitensis strain B115 as a vaccine strain is also discussed.
\end{abstract}

\section{Introduction}

All smooth strains of Brucella bear on their smooth lipopolysaccharide (S-LPS) two distinct antigenic specificities defined either by polyclonal or monoclonal antibodies (mAbs) and designated $\mathrm{A}$ and $\mathrm{M}$ (Bundle et al., 1989; Douglas \& Palmer, 1988; Meikle et al., 1989; Wilson \& Miles, 1932). The relative amounts of the A and $\mathbf{M}$ specificities vary among smooth Brucella strains and they are absent on rough ( $R$ ) strains lacking $O$ side chain (Alton et al., 1988). These smooth Brucella strains are classified into three serotypes, i.e. $\mathbf{A}^{+} \mathbf{M}^{-}, \mathrm{A}^{-} \mathbf{M}^{+}$and

*Author for correspondence. Present address: Institut National de la Recherche Agronomique, Laboratoire de Pathologie Infectieuse et Immunologie, 37380 Nouzilly, France. Tel. 474278 67; fax 474277 79.

Abbreviations: mAb, monoclonal antibody; O-PS, O-polysaccharide; R-LPS, rough lipopolysaccharide; S-LPS, smooth lipopolysaccharide.
$\mathrm{A}^{+} \mathrm{M}^{+}$, according to slide agglutination using $\mathrm{A}$ and $\mathrm{M}$ monospecific polyclonal sera. These agglutination results correspond to strains expressing mainly the $\mathrm{A}$ or $\mathrm{M}$ antigens or both antigens in nearly equivalent amounts. These characteristics may be abbreviated as, respectively, $\mathrm{A} \gg \mathrm{M}, \mathrm{M} \gg \mathrm{A}$ or A,M. mAbs to S-LPS of Brucella spp. have been reported with specificity for the A-LPS epitope, the M-LPS epitope and for common epitopes (C) cross-reacting or not with $Y$. enterocolitica $0: 9$ S-LPS (Bundle et al., 1989; Cloeckaert et al., 1992a; Douglas \& Palmer, 1988; Garin-Bastuji et al., 1990; Limet et al., 1989; Palmer \& Douglas, 1989).

The $B$. melitensis strain $\mathrm{B} 115$ is a rough strain by classical criteria, i.e. microscopic observation of colonies by obliquely reflected light, staining of $\mathbf{R}$ colonies with crystal violet and absence of agglutination by monospecific sera to the $A$ and $M$ antigens of Brucella (Alton et al., 1988). Absence of reactivity of B. melitensis B115 bacterial cells with S-LPS specific mAbs has also been shown by colony-blot ELISA (Roop et al., 1987), 
coagglutination (Vizcaino \& Fernandez-Lago, 1992) and ELISA and immunoelectron microscopy (Cloeckaert et al., 1992b). Jones et al. (1973) showed that injection of living or killed cells of $B$. melitensis strain B115 into rabbits produced low-titre agglutinins to smooth cells. However, they were unable to extract S-LPS from this strain by the phenol/water/chloroform/petroleum ether method of Galanos et al. (1969). mAbs specific for S-LPS were obtained by fusion of the NSO myeloma with spleen cells from mice infected with $B$. melitensis B115 (Cloeckaert et al., 1990) or mice immunized with the cell wall fraction of $B$. melitensis B115 (unpublished data). By using one of these mAbs (12G12), of IgG1 isotype, which was specific for O-polysaccharide (O-PS) and reacted with S-LPS of both A and M dominant Brucella strains, we were able to demonstrate by immunoelectron microscopy the expression of O-PS in this rough bacterium (Cloeckaert et al., 1992b). O-PS was localized intracellularly and not exposed at the cell surface as in the smooth Brucella strains. This mAb reacted in ELISA and immunoblotting with sonicated $B$. melitensis B115 bacteria or their cell wall fraction and was protective in mice against smooth virulent strains of $B$. abortus and $B$. melitensis (Cloeckaert et al., 1992a). In the present study, we report the characterization of the $\mathrm{mAbs}$ derived from mice infected with $B$. melitensis $\mathrm{B} 115$, and the reactivity of S-LPS extracted from this rough strain with mAbs specific for A, M and C epitopes compared to S-LPS of A and $\mathrm{M}$ dominant smooth Brucella strains.

\section{Methods}

Bacterial strains. B. melitensis rough $(\mathrm{R})$ strain $\mathrm{B} 115$ and $B$. melitensis $16 \mathrm{M}\left(\mathrm{A}^{-} \mathrm{M}^{+}\right)$, B. melitensis $\mathrm{M} 3\left(\mathrm{~A}^{+} \mathrm{M}^{+}\right)$, B. abortus $99\left(\mathrm{~A}^{+} \mathrm{M}^{-}\right), B$. abortus $\mathbf{B} 3\left(\mathrm{~A}^{+} \mathbf{M}^{-}\right)$smooth (S) strains were obtained from the Institut National de la Recherche Agronomique, Laboratoire de Pathologie Infectieuse et d'Immunologie, Nouzilly, Tours, France. Purity and $R$ and $\mathrm{S}$ phenotypes were clearly established by standard procedures (Alton et al., 1988). The R phenotype of B. melitensis B115 strain has been found to be stable over a period of 18 years (Alton et al., 1988; Jones et al., 1973). Y. enterocolitica O:9 was obtained from G. Wauters (Microbiology Department, Catholic University of Louvain).

LPS fractions. S-LPS fractions of B. melitensis $16 \mathrm{M}, B$. abortus B3 and $Y$. enterocolitica $O: 9$ were prepared by the phenol/water method (Leong et al., 1970). R-LPS fraction of B. melitensis B115 was obtained by the phenol/water/chloroform/petroleum ether method of Galanos et al. (1969). Proteinase K-digested S-LPS fractions of $B$. melitensis $16 \mathrm{M}$, B. melitensis $\mathrm{M} 3, B$. abortus 99 and B. melitensis B115 were prepared as described previously (Cloeckaert et al., 1992b; GarinBastuji et al., 1990). S-LPS fraction of $B$. melitensis B115 was isolated from cell walls. S-LPS fractions of $B$. melitensis $16 \mathrm{M}, B$. melitensis M3 and $B$. abortus 99 were isolated from whole smooth bacterial cells. O polysaccharide (O-PS) of $B$. abortus 99 was prepared as described previously (Jacques et al., 1991; Zygmunt et al., 1988).

$m A b s$. Anti-S-LPS mAbs derived from mice infected with $B$. melitensis B115 were produced as described previously (Cloeckaert et al., 1990, 1992b). Screening and specificity were determined by immunoblot analysis and ELISA using cell walls and R-LPS of $B$. melitensis B115 and S-LPS of B. melitensis and B. abortus S strains. The mAbs specific for the A epitope (mAb 04F9) and $M$ epitope (mAb 2E11) were produced as described previously (Limet et al., 1989).

ELISA. ELISA was performed as described previously (Cloeckaert et al., 1990, 1992b). S-LPS was coated on microtitre plates (Greiner Labortechnic, Stuttgart, Germany) by overnight incubation at a concentration of $4 \mu \mathrm{g} \mathrm{ml}^{-1}$. Hybridoma supernatants or ascitic fluids were serially diluted ( 1 in 10,1 in 30,1 in 90, up to 1 in 21 870). Binding of antibodies to S-LPS was revealed by successive incubations with rabbit anti-mouse immunoglobulin serum and peroxidase-conjugated protein A (Cloeckaert et al., 1990, 1992b) or with peroxidaseconjugated goat anti-mouse immunoglobulins (Kirkegaard \& Perry Laboratories).

Immunoblot techniques. Immunoblotting was performed as described previously (Cloeckaert et al., 1990, 1992a,b).

$m A b$ isotypes. These were determined by direct latex agglutination immunoassay of the culture supernatants. Latex particles were coated with rat monoclonal anti-mouse IgG1, IgG2a, IgG2b, IgG3, IgM and polyclonal anti-mouse $\operatorname{IgA}$ according to a protocol similar to that described by Limet et al. (1988).

\section{Results}

\section{Monoclonal antibodies}

S-LPS mAbs derived from mice infected with $B$. melitensis B115 were characterized by ELISA using two types of S-LPS, i.e. S-LPS of A dominant strain $B$. abortus $\mathrm{B} 3(\mathrm{~A} \gg \mathrm{M})$ and $\mathrm{M}$ dominant strain $B$. melitensis $16 \mathrm{M}(\mathrm{M} \gg \mathrm{A})$. According to their reactivity in ELISA, these $\mathrm{mAbs}$ could be divided into three groups (Table 1). Typical binding of one $\mathrm{mAb}$ of each group is given in Fig. 1. Nine $\mathrm{mAbs}$ of IgG1 and IgM isotypes recognized epitopes expressed in equal amount on S-LPS of the A and $\mathrm{M}$ dominant Brucella serotypes and are designated as specific for a common epitope (C). These mAbs gave the same antibody titre and approximately the same maximal absorbance in ELISA with the two S-LPS types at the coating concentration used. Another group of ten $\mathrm{mAbs}$ of IgG3 and IgG2a isotypes reacted with both S-LPS types according to the maximal absorbance in ELISA but a higher titre was observed with S-LPS of the $\mathrm{M}$ dominant strain $B$. melitensis $16 \mathrm{M}$. They are designated as specific for one or several epitopes common to both S-LPS types but more abundant or accessible to antibody in S-LPS of the M dominant strain $(C M>A)$. The last group consisted of three mAbs which were highly specific for S-LPS of the M dominant strain (M) and these were of the IgG3 and IgM isotypes. Reactivity of the mAbs was confirmed by immunoblotting using the two S-LPS types (not shown).

All $\mathrm{mAbs}$ obtained except two specific for the $\mathbf{M}$ epitope (mAbs 18B04 and 04F03) reacted with O-PS of $B$. abortus 99. They did not bind to R-LPS of $B$. melitensis B115 and thus recognize epitopes of the O-PS. 


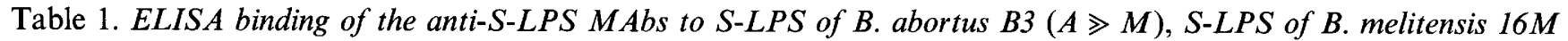
$(M \gg A), R-L P S$ of $B$. melitensis B115 and O-PS of B. abortus 99

\begin{tabular}{|c|c|c|c|c|c|c|c|}
\hline \multirow{3}{*}{$\begin{array}{c}\text { mAbs } \\
\text { (hybridoma supernatant) }\end{array}$} & \multirow[b]{3}{*}{ Isotype } & \multicolumn{2}{|c|}{ S-LPS B3 } & \multicolumn{2}{|c|}{ S-LPS $16 \mathrm{M}$} & \multirow{3}{*}{$\begin{array}{l}\text { R-LPS B115 } \\
\text { Absorbancet }\end{array}$} & \multirow{3}{*}{$\begin{array}{c}\text { O-PS } 99 \\
\text { Absorbance* }\end{array}$} \\
\hline & & & Maximum & & Maximum & & \\
\hline & & Titre & absorbance* & Titre & absorbance & & \\
\hline \multicolumn{8}{|l|}{$S-L P S(C) \dagger$} \\
\hline 05D01 & IgG1 & 21870 & $3 \cdot 138$ & 21870 & $3 \cdot 174$ & 0.066 & $1 \cdot 752$ \\
\hline 07F09 & IgG1 & 7290 & $2 \cdot 934$ & 7290 & $3 \cdot 213$ & $0 \cdot 108$ & $1 \cdot 731$ \\
\hline $12 \mathrm{G} 12$ & IgG1 & $>21870$ & $3 \cdot 802$ & $>21870$ & 3.398 & 0.080 & 1.566 \\
\hline $13 \mathrm{~A} 09$ & IgG1 & 21870 & $3 \cdot 139$ & 21870 & $3 \cdot 287$ & $0 \cdot 157$ & $1 \cdot 790$ \\
\hline $14 \mathrm{~F} 12$ & IgG1 & $>21870$ & $3 \cdot 128$ & $>21870$ & 3.082 & 0.093 & 1.719 \\
\hline 16F01 & IgG1 & 21870 & $3 \cdot 168$ & 21870 & $3 \cdot 239$ & $0 \cdot 103$ & $1 \cdot 708$ \\
\hline 13G11 & IgM & $>21870$ & 1.644 & $>21870$ & $1 \cdot 874$ & 0.024 & $1 \cdot 124$ \\
\hline O5E11 & IgM & 90 & 1.207 & 90 & $0 \cdot 824$ & 0.030 & $1 \cdot 107$ \\
\hline $14 \mathrm{H} 09$ & IgM & 21870 & $2 \cdot 056$ & 21870 & $2 \cdot 364$ & 0.028 & $1 \cdot 320$ \\
\hline \multicolumn{8}{|l|}{$S-L P S(C M>A) \dagger$} \\
\hline $15 \mathrm{~B} 10$ & $\operatorname{IgG} 2 \mathrm{a}$ & 7290 & $3 \cdot 023$ & $>21870$ & $3 \cdot 581$ & $0 \cdot 080$ & $1 \cdot 720$ \\
\hline 02B05 & IgG3 & 810 & $2 \cdot 882$ & $>21870$ & $3 \cdot 515$ & $0 \cdot 047$ & 1.653 \\
\hline 03D03 & IgG3 & 810 & $3 \cdot 536$ & 21870 & 3.099 & 0.063 & 1.617 \\
\hline 04A05 & IgG3 & 270 & $2 \cdot 933$ & 21870 & $3 \cdot 399$ & $0 \cdot 076$ & $1 \cdot 670$ \\
\hline $11 \mathrm{H} 03$ & IgG3 & 270 & $2 \cdot 963$ & 21870 & 3.068 & 0.007 & 1.842 \\
\hline $12 \mathrm{~B} 12$ & IgG3 & 2430 & $3 \cdot 137$ & 21870 & $3 \cdot 135$ & $0 \cdot 080$ & 1.589 \\
\hline $17 \mathrm{H} 02$ & IgG3 & 2430 & $3 \cdot 215$ & $>21870$ & $3 \cdot 375$ & 0.020 & 1.705 \\
\hline 01F08 & IgG3 & 810 & $2 \cdot 808$ & 21870 & $3 \cdot 238$ & 0.019 & 1.797 \\
\hline $08 \mathrm{C} 06$ & IgG3 & 810 & $2 \cdot 825$ & 7290 & $3 \cdot 101$ & $0 \cdot 081$ & 1.672 \\
\hline 08B07 & IgG3 & 2430 & $1 \cdot 712$ & 21870 & $2 \cdot 109$ & 0.099 & $1 \cdot 423$ \\
\hline \multicolumn{8}{|l|}{$S-L P S(M) \dagger$} \\
\hline 03E05 & IgG3 & 30 & $1 \cdot 377$ & $>21870$ & $3 \cdot 396$ & 0.023 & 1.771 \\
\hline 18B04 & IgM & 10 & 0.461 & 21870 & $3 \cdot 325$ & 0.039 & 0.032 \\
\hline $04 \mathrm{~F} 03$ & IgM & 10 & $0 \cdot 592$ & $>21870$ & 3.909 & $0 \cdot 101$ & $0 \cdot 115$ \\
\hline
\end{tabular}

* Maximal absorbance after blank value subtraction.

$\dagger(C),(C M>A),(M)$ : specific for a common epitope (C), an epitope common for both S-LPS types but more abundant on the M S-LPS type (C M > A), and for the $M$ epitope (M), respectively.

$\ddagger$ Absorbance value of a $1 / 2$ hybridoma supernatant dilution.

Cross-reactivity with $Y$. enterocolitica $0: 9$ S-LPS

In ELISA, in contrast to $\mathrm{mAb} 04 \mathrm{F9}$, which is specific for the A epitope, the mAbs specific for common and $M$ epitopes, which were derived from mice infected with $B$. melitensis B115, showed little or no reactivity with S-LPS extracted from the cross-reactive strain $Y$. enterocolitica O:9 (Fig. 2). This was also confirmed by immunoblot analysis (not shown).

\section{Characterization of S-LPS of B. melitensis B115}

(i) Immunoblot analysis. Proteinase K-digested S-LPS fraction of $B$. melitensis $\mathrm{B} 115$ was compared by immunoblotting using mAbs $12 \mathrm{G} 12$ (IgG1) specific for the $\mathrm{C}$ epitope (mAb-C), 04F9 (IgG2a) specific for the A epitope (mAb-A) and 2E11 (IgG3) specific for the M epitope (mAb-M), to Proteinase K-digested S-LPS extracted from $B$. abortus $99\left(\mathrm{~A}^{+} \mathrm{M}^{-}\right.$serotype), B. melitensis $16 \mathrm{M}$ ( $\mathrm{A}^{-} \mathrm{M}^{+}$serotype) and $B$. melitensis $\mathrm{M} 3\left(\mathrm{~A}^{+} \mathrm{M}^{+}\right.$serotype) smooth strains (Fig. 3). mAb-C revealed all S-LPS types strongly. mAb-A revealed only S-LPS from the A dominant strains $B$. abortus $99\left(\mathrm{~A}^{+} \mathrm{M}^{-}\right)$and $B$. melitensis M3 $\left(\mathrm{A}^{+} \mathbf{M}^{+}\right)$. mAb-M strongly revealed S-LPS of the $\mathbf{M}$ dominant strain $B$. melitensis $16 \mathrm{M}\left(\mathrm{A}^{-} \mathrm{M}^{+}\right)$, S-LPS of the B. melitensis strain M3 $\left(\mathrm{A}^{+} \mathrm{M}^{+}\right)$and, very weakly, S-LPS of the rough $B$. melitensis strain B115.

(ii) ELISA. Immunoblotting results were confirmed by ELISA using the same S-LPS fractions. mAb-C bound approximately equally well to the four strains tested (Fig. 4). The maximal absorbance observed with this $\mathrm{mAb}$ was always higher than or equal to that of the other mAbs. mAb-A bound to S-LPSs of the A dominant strains $B$. abortus $99\left(\mathrm{~A}^{+} \mathbf{M}^{-}\right)$and $B$. melitensis $\mathrm{M} 3$ $\left(\mathrm{A}^{+} \mathrm{M}^{+}\right)$, in agreement with serotyping results using $\mathrm{A}$ and $M$ monospecific sera. $\mathrm{mAb}$-A bound also to S-LPS of the $\mathrm{M}$ dominant strain $B$. melitensis $16 \mathrm{M}\left(\mathrm{A}^{-} \mathrm{M}^{+}\right)$but the maximal absorbance observed was weaker than that observed for mAb-M. mAb-M bound to the S-LPSs of $\mathrm{M}$ dominant strain $B$. melitensis $16 \mathrm{M}\left(\mathrm{A}^{-} \mathrm{M}^{+}\right)$and $\mathrm{A}$ dominant strain $B$. melitensis $\mathbf{M} 3\left(\mathrm{~A}^{+} \mathbf{M}^{+}\right)$. In contrast to $\mathrm{mAb}-\mathrm{C}, \mathrm{mAb}-\mathrm{M}$ and $\mathrm{mAb}-\mathrm{A}$ bound very weakly to S-LPS of rough $B$. melitensis strain B115. 

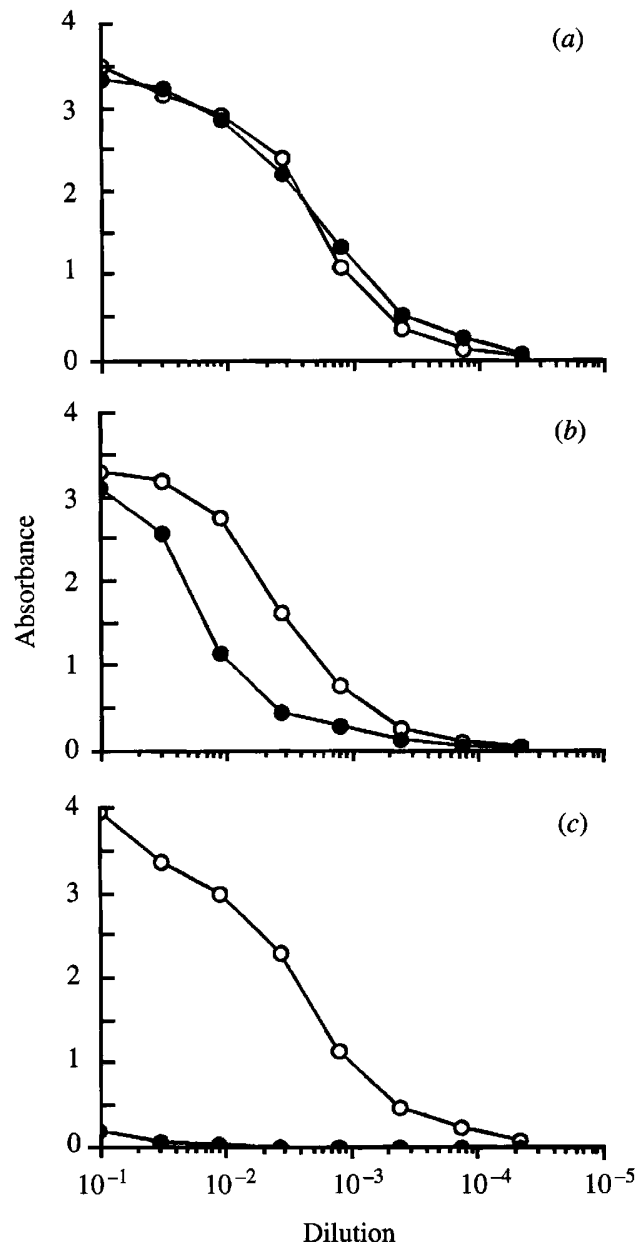

Fig. 1. Binding of anti-S-LPS mAbs (hybridoma supernatants) $12 \mathrm{G} 12$ (C epitope) (a), 12B12 (CM > A epitope (b) and 04F03 (M epitope) (c) to S-LPS of B. abortus $\mathrm{B} 3\left(\mathrm{~A}^{+} \mathrm{M}^{-}\right)(0)$ and $B$. melitensis $16 \mathrm{M}\left(\mathrm{A}^{-} \mathrm{M}^{+}\right)$ (O). Rabbit anti-mouse immunoglobulins and peroxidase-conjugated protein A were used to detect antibody reactivity.

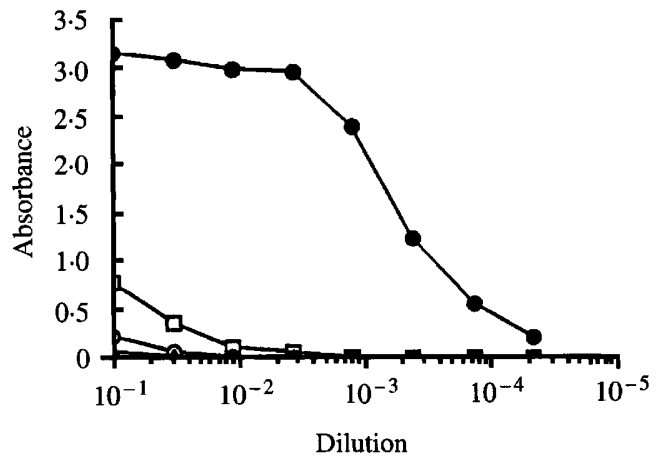

Fig. 2. Binding of anti-S-LPS mAbs (hybridoma supernatants) $12 \mathrm{G} 12$ (C epitope) ( $\square$ ), 12B12 (CM > A epitope) $(\bigcirc), 04 F 03$ (M epitope) $(\triangle)$ and 04F9 (A epitope) (O) to S-LPS of $Y$. enterocolitica O:9. Rabbit anti-mouse immunoglobulins and peroxidase-conjugated protein $\mathrm{A}$ were used to detect antibody reactivity.
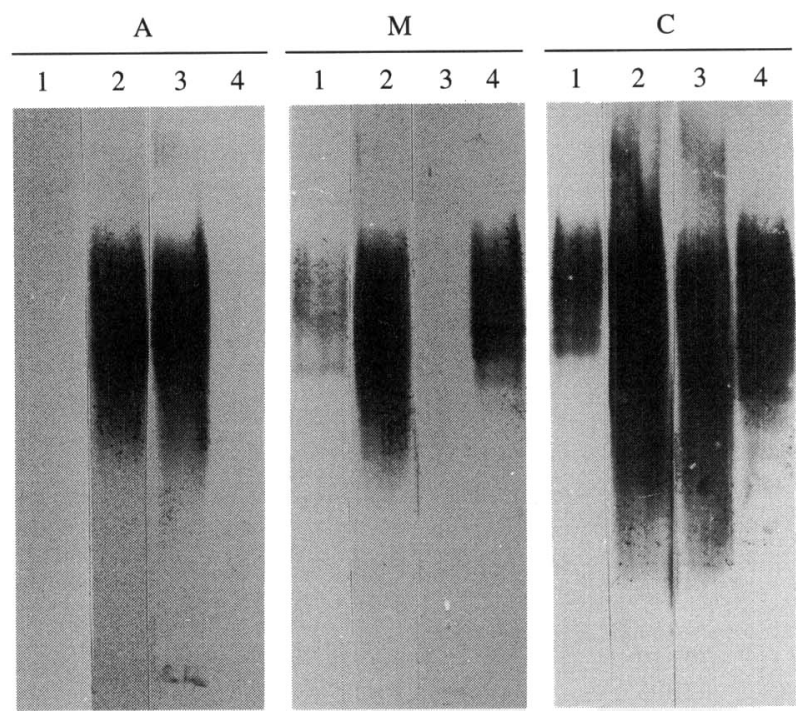

Fig. 3. Immunoblot of proteinase K-treated S-LPS of $B$. melitensis B115 (R) (lane 1), B. melitensis $\mathrm{M} 3\left(\mathrm{~A}^{+} \mathrm{M}^{+}\right)$(lane 2), B. abortus 99 $\left(\mathrm{A}^{+} \mathrm{M}^{-}\right)$(lane 3 ) and $B$. melitensis $16 \mathrm{M}\left(\mathrm{A}^{-} \mathrm{M}^{+}\right)$(lane 4) with $\mathrm{mAb}-\mathrm{A}$ 04F9 (A), mAb-M 2E11 (M) and mAb-C 12G12 (C).

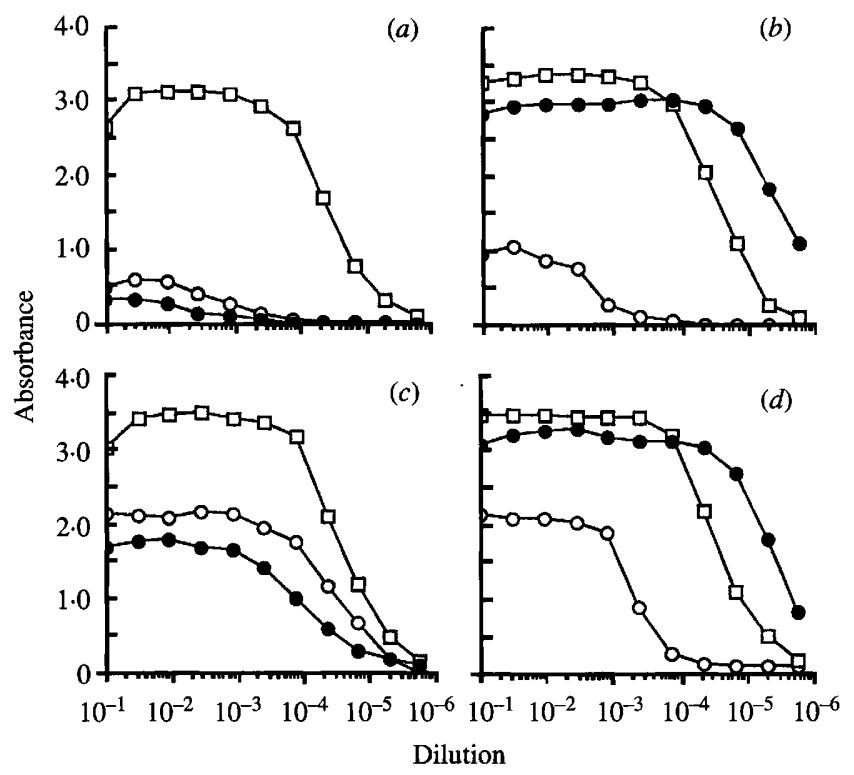

Fig. 4. Binding of mAb-A 04F9 (O), mAb-M 2E11 (O) and $\mathrm{mAb}-\mathrm{C}$ $12 \mathrm{G} 12(\square)$ (ascitic fluids) to S-LPS of $B$. melitensis B115 (R) (a), B. abortus $99\left(\mathrm{~A}^{+} \mathrm{M}^{-}\right)(b)$, B. melitensis $16 \mathrm{M}\left(\mathrm{A}^{-} \mathrm{M}^{+}\right)(c)$ and $B$. melitensis M3 $\left(\mathrm{A}^{+} \mathrm{M}^{+}\right)(d)$. Peroxidase-conjugated goat anti-mouse immunoglobulins were used to detect antibody reactivity.

\section{Discussion}

mAbs specific for S-LPS were produced by fusion of spleen cells from mice infected with the rough $B$. melitensis B115 strain and the NSO myeloma (Cloeckaert et al., 1990). The reactivity in ELISA with O-PS and absence of reactivity with R-LPS indicate that these mAbs were specific for O-PS epitopes. Immunoblotting 
with R- (not shown) and S-LPS confirmed the O-PS specificity. Most of the mAbs produced were specific for common epitopes ( $\mathrm{C}$ and $\mathrm{C} M>A$ ) shared by the Brucella $\mathrm{A}$ and $\mathrm{M}$ dominant S-LPS types. The fact that the $\mathrm{C}$ epitope induced mainly $\mathrm{IgGl} \mathrm{mAbs}$ and the $\mathrm{C}$ $\mathrm{M}>\mathrm{A}$ epitope mainly IgG3 mAbs remains to be explained. Two IgM mAbs highly specific for M LPS did not react with O-PS in ELISA since the latter was prepared from the A dominant strain $B$. abortus 99 . All mAbs derived from mice infected with $B$. melitensis B115 showed little or no cross-reactivity in ELISA with $Y$. enterocolitica O:9 S-LPS. The weak or absent crossreactivity of $\mathrm{mAbs}$ specific for common and $M$ epitopes with $Y$. enterocolitica O:9 S-LPS was also shown by Palmer \& Douglas (1989). mAbs showing a crossreactivity with $Y$. enterocolitica $\mathrm{O}: 9$ generally recognize the A epitope (Douglas \& Palmer, 1988) and this specificity is shown by mAb-A 04F9. Our results also suggest that these mAbs may be particularly useful for typing smooth Brucella strains.

The fact that $\mathrm{mAb}-\mathrm{C}$ reacted with all Brucella S-LPS types (ELISA and immunoblotting) but that mAb-A did not react with $B$. melitensis B115 S-LPS while mAb-M reacted very weakly with this strain suggests that the O-PS expressed in rough $B$. melitensis B115 strain bears mainly $C$ epitopes and very few $M$ epitopes. mAbs were initially screened by ELISA using $B$. melitensis B115 antigen fractions, with rabbit anti-mouse immunoglobulins and peroxidase-conjugated protein $\mathrm{A}$ as secondary reagents (Cloeckaert et al., 1990, 1992b). In these conditions mAb-M showed a better reactivity (higher absorbance value) against $B$. melitensis $\mathrm{B} 115$ than was obtained with peroxidase-conjugated goat anti-mouse immunoglobulins as shown in this study. Nevertheless, mAb-A still showed very weak reactivity against S-LPS of $B$. melitensis B115 when using rabbit anti-mouse immunoglobulins and conjugated protein $\mathrm{A}$ as secondary reagents (data not shown). Absence or very weak reactivity of this S-LPS with $\mathrm{mAb}-\mathrm{A}$ and the fact that the mAbs specific for $\mathrm{C}$ and $\mathrm{C} M>A$ epitopes showed little or no cross-reactivity with $Y$. enterocolitica O:9 S-LPS suggest that O-PS from this rough strain could possibly be useful to distinguish $Y$. enterocolitica $0: 9$ infection from Brucella infection. Sera from mice infected with $B$. melitensis B115 (five mice infected intraperitoneally with $10^{7}$ c.f.u. were tested at 1 month post-challenge) also showed very weak antibody reactivity (not statistically different from negative control mice) or did not react with S-LPS of $Y$. enterocolitica O:9 in ELISA (data not shown) but showed high antibody reactivity against $B$. melitensis 16M S-LPS (titre between $1 / 500$ and $1 / 1000$ for an absorbance value of 1.0).

The Brucella O-PS structure has been defined as homopolymers of 4,6-dideoxy-4-formamido- $\alpha$-D-manno- pyranose residues. O-PS from A dominant strains is a linear $\alpha$-1,2-linked polymer with about $2 \%$ of $\alpha-1,3-$ linkages, while O-PS from M dominant strains is a linear polymer of pentasaccharide repeating units containing one $\alpha$-1,3-linked and four $\alpha$-1,2-linked monosaccharide residues (Bundle et al., 1989; Meikle et al., 1989). Apparently the $\alpha-1,3$-linkage is mainly involved in the structure recognized by $\mathbf{M}$ specific $\mathrm{mAbs}$. This is reinforced by the fact that $\mathrm{mAbs}$ specific for $\mathrm{M}$ dominant S-LPS showed no reactivity against S-LPS of $Y$. enterocolitica O:9. The structure of the O-PS of $Y$. enterocolitica $\mathrm{O}: 9$ is identical to that of Brucella A dominant O-PS except that no $\alpha-1,3$ linkages are detected (Meikle et al., 1989). The $\alpha$-1,2-linkage may be involved in the structure recognized by the A-specific mAb. This $\mathrm{mAb}$ also showed high reactivity against $Y$. enterocolitica $\mathrm{O}: 9 \mathrm{~S}-\mathrm{LPS}$. Reactivity of mAbs specific for $\mathrm{C}$ epitopes is more difficult to explain according to the structures of the O-PS described in the literature since they showed high reactivity against S-LPS and O-PS of both A and M dominant Brucella strains but weak reactivity against $Y$. enterocolitica O:9 S-LPS. The lack of cross-reactivity with $Y$. enterocolitica $\mathrm{O}: 9$ also indicates that using serum antibody response to S-LPS of $Y$. enterocolitica $O: 9$ as a criterion for detecting antibody response against $B$. abortus O-PS in infected animals (Schurig et al., 1991) may not be sufficient. Since, according to ELISA and immunoblotting results, O-PS from the rough $B$. melitensis B115 strain seems to bear mainly common epitopes to $\mathrm{A}$ and $\mathrm{M}$ dominant smooth strains, it may be that its structure is different from the structures of the A and M S-LPS types described by Bundle et al. (1989) and Meikle et al. (1989). Determining the structure of this O-PS will help determine what kind of epitopes are recognized by $\mathrm{mAb}-\mathrm{C}$.

The fact that O-PS expressed in B. melitensis B115 strain bears mainly common epitopes and consequently the fact that it induces antibodies mainly against common epitopes is interesting when considering vaccine development. Vaccination actually performed in animals is based on live attenuated or killed smooth Brucella strains which induce an antibody response to S-LPS. Serodiagnosis by conventional tests does not permit distinction between vaccinated and infected animals because in these tests the S-LPS is the major immunodominant antigen. IgG and IgM mAbs specific for the $\mathrm{C}$ epitope derived from $B$. melitensis B115 infected mice were found to be protective in mice against challenge with virulent $B$. abortus and $B$. melitensis smooth strains (Cloeckaert et al., 1992a). It was also shown by Dubray (1981) that the sodium dodecyl sulphate insoluble (SDSI) cell wall fraction from B. melitensis B115 was the only SDS-I fraction among other Brucella rough strain SDS-I fractions to show a partial protective activity in mice 
against $B$. abortus, probably mediated by anti-S-LPS antibodies induced by this fraction. This fraction has been shown by use of mAb-C to contain a small quantity of S-LPS or O-PS (unpublished result). Cell walls from $B$. melitensis B115 were also shown to induce antibodies specific for S-LPS (unpublished result). For these reasons, and because B. melitensis B115 (Jones et al., 1973), like other rough Brucella strains (Alton, 1960; Harmon et al., 1988; Kreutzer \& Robertson, 1979; Schurig et al., 1991; Tobias et al., 1992), is much less virulent than smooth Brucella strains, B. melitensis B115 could possibly be used as a vaccine strain if distinction between vaccinated and infected animals could be based on specific detection in infected animals of antibodies against the A-LPS epitopes, as for example by use of competitive ELISA and/or O-PS of $Y$. enterocolitica O:9. High antibody reactivity in ELISA against $Y$. enterocolitica O:9 S-LPS has been observed in sheep and cattle experimentally infected with $B$. melitensis and $B$. abortus respectively (unpublished results).

We are most grateful to J. M. Verger and M. Grayon for culture and control of bacterial strains. We thank G. Bézard, A. Van Rompaye, and J. Van Broeck for expert technical assistance. A.C. was supported by the Institut National pour l'Encouragement de la Recherche Scientifique dans l'Industrie et l'Agriculture.

\section{References}

Alton, G. G. (1960). The occurrence of dissociated strains of Brucella melitensis in the milk of goats in Malta. Journal of Comparative Pathology 70, 10-17.

Alton, G. G., Jones, L. M., Angus, R. D. \& Verger, J. M. (1988). Techniques for the Brucellosis Laboratory. Paris: Institut National de la Recherche Agronomique.

Bundle, D. R., Cherwonogrodzky, J. W., Gidney, M. A. J., Meikle, P. J., Perry, M. B. \& Peters, T. (1989). Definition of Brucella A and $\mathrm{M}$ epitopes by monoclonal typing reagents and synthetic oligosaccharides. Infection and Immunity 57, 2829-2836.

Cloeckaert, A., de Wergifosse, P., Dubray, G. \& Limet, J. N. (1990). Identification of seven surface-exposed Brucella outer membrane proteins by use of monoclonal antibodies: immunogold labeling for electron microscopy and enzyme-linked immunosorbent assay. Infection and Immunity 58, 3980-3987.

Cloeckaert, A., Jacques, I., De Wergifosse, P., Dubray, G. \& Limet, J. N. (1992a). Protection against Brucella melitensis or Brucella abortus in mice with immunoglobulin $\mathrm{G}$ (IgG), IgA and IgM monoclonal antibodies specific for a common epitope shared by the Brucella $\mathrm{A}$ and $\mathrm{M}$ smooth lipopolysaccharides. Infection and Immunity 60, 312-315.

Cloeckaert, A., Zygmunt, M. S., Nicolle, J.-C., Dubray, G. \& LIMET, J. N. (1992b). O-chain expression in the rough Brucella melitensis strain B115: induction of O-polysaccharide specific monoclonal antibodies and intracellular localization demonstrated by immunoelectron microscopy. Journal of General Microbiology 138, 1211-1219.
Douglas, J. T. \& Palmer, D. A. (1988). Use of monoclonal antibodies to identify the distribution of $\mathrm{A}$ and $\mathrm{M}$ epitopes on smooth Brucella species. Journal of Clinical Microbiology 26, 1353-1356.

DURRAY, G. (1981). Etude ultrastructurale et biochimique des enveloppes des bactéries du genre Brucella. PhD thesis, Université de Paris-Sud.

Galanos, C., Luderitz, O. \& WeStPhal, O. (1969). A new method for the extraction of R-lipopolysaccharides. European Journal of Biochemistry 9, 245-249.

Garin-Bastui, B., Bowden, R. A., Dubray, G. \& Limet, J. N. (1990). Sodium dodecyl sulfate-polyacrylamide gel electrophoresis and immunoblotting analysis of smooth-lipopolysaccharide heterogeneity among Brucella biovars related to $\mathrm{A}$ and $\mathbf{M}$ specificities. Journal of Clinical Microbiology 28, 2169-2174.

HaRmon, B. G., Adams, L. G. \& Frey, M. (1988). Survival of rough and smooth strains of Brucella abortus in bovine mammary gland macrophages. American Journal of Veterinary Research 49, 1092-1097.

JACQUES, I., OLIVIER-BERNARDIN, V. \& DUBRAY, G. (1991). Induction of antibody and protective responses in mice by Brucella $\mathrm{O}$ polysaccharide-BSA conjugate. Vaccine 9, 896-900.

JoNeS, L. M., DiAZ, R. \& TAYlOR, A. G. (1973). Characterization of allergens prepared from smooth and rough strains of Brucella melitensis. British Journal of Experimental Pathology 54, 492-508.

KREUTZER, D. L. \& RoBERTSON, D. C. (1979). Surface macromolecules and virulence in intracellular parasitism: comparison of cell envelope components of smooth and rough strains of Brucella abortus. Infection and Immunity 23, 819-837.

Leong, D., Diaz, R., MilneR, K., RudbaCh, J. \& Wilson, J. B. (1970). Some structural and biological properties of Brucella endotoxin. Infection and Immunity 1, 174-182.

Limet, J. N., Berbinschi, A., Cloeckaert, A., Cambiaso, C. L. \& Masson, P. L. (1988). Longitudinal study of brucellosis in mice by immunoassay of lipopolysaccharide-related antigens in blood and urine. Journal of Medical Microbiology 26, 37-45.

Limet, J. N., Bosseray, N., Garin-Bastuj, B., Dubray, G. \& Plommet, M. (1989). Humoral immunity in mice mediated by monoclonal antibodies against the $\mathrm{A}$ and $\mathrm{M}$ antigens of Brucella. Journal of Medical Microbiology 30, 37-43.

Meikle, P. J., Perry, M. B., Cherwonogrodzky, J. W. \& Bundle, D. R. (1989). Fine structure of A and $M$ antigens from Brucella biovars. Infection and Immunity 57, 2820-2828.

Palmer, D. A. \& Douglas, J. T. (1989). Analysis of Brucella lipopolysaccharide with specific and cross-reacting monoclonal antibodies. Journal of Clinical Microbiology 27, 2331-2337.

Roop, R. M., II, Preston-Moore, D., BAGCHI, T. \& SChurig, G. G. (1987). Rapid identification of smooth Brucella species with a monoclonal antibody. Journal of Clinical Microbiology 25, 2090-2093.

Schurig, G. G., Roop, R. M., II, Bagchi, T., Boyle, S., Buhrman, D. \& SRIRANGanathan, N. (1991). Biological properties of RB51; a stable rough strain of Brucella abortus. Veterinary Microbiology $\mathbf{2 8}$, 171-188.

Tobias, L., Schurig, G. G. \& Cordes, D. O. (1992). Comparative behaviour of Brucella abortus strains 19 and RB51 in the pregnant mouse. Research in Veterinary Science 53, 179-183.

Vizcaino, N. \& Fernandez-Lago, L. (1992). A rapid and sensitive method for the identification of Brucella species with a monoclonal antibody. Research in Microbiology 143, 513-518.

WILSON, G. S. \& MILES, A. A. (1932). The serological differentiation of smooth strains of the Brucella group. British Journal of Experimental Pathology 13, 1-13.

Zygmunt, M. S., Dubray, G., Bundle, D. R. \& Perry, M. B. (1988). Purified native haptens of Brucella abortus B19 and B. melitensis $16 \mathrm{M}$ reveal the lipopolysaccharide origin of the antigens. Annales de l'Institut Pasteur/Microbiologie 139, 421-433. 